\title{
Echocardiographic Right Heart Study in Patients with Chronic Obstructive Pulmonary Disease
}

\author{
Kazi Shamim Al Mamun ${ }^{* 1}$, Mohammad Ibrahim Chowdhury², Muhammad Khurshed Alam³ \\ Syedul Alam Khuryshiं, S M Ifteakharul Islam ${ }^{5}$
}

Abstract:

Introduction: Chronic obstructive pulmonary disease (COPD) has considerable effects on cardiac functions, including those of the right ventricle, left ventricle, and pulmonary blood vessels. Most of the increased mortality associated with COPD is due to cardiac involvement. Echocardiography provides a rapid, noninvasive, portable, and accurate method to evaluate the cardiac changes. Aims: We aimed to prospectively study the patients with diagnosed COPD with echocardiogram for evaluating the right heart. Materials \& Methods: Our study was an observational, cross sectional study was done on 50 patients with COPD who were admitted at Department of Cardiology, CMCH and underwent echocardiographic evaluation from November 2017 -October 2018. All echocardiogaphic parameters focused on right heart and its function were assessed. Results: Out of total 50 COPD patients studied, majority of them were male (46 patients, $92 \%)$. The mean age group of the studied patients was $58.4 \pm 7.7$ years. Pulmonary hypertension defined as $s P A P>30 \mathrm{mmHg}$ was evident in all of the patients; with 30 patients (60\%), $14(28 \%)$ and $6(12 \%)$ patients having severe, moderate and mild pulmonary hypertension respectively. $R V$ dysfunction was evident with reduced average TAPSE values $(1.59 \pm 0.38 \mathrm{~cm})$ and elevated RIMP values $(0.58 \pm 0.16)$. Conclusion: Majority of COPD patients had evidence of pulmonary hypertension. Echocardiogram can be a helpful tool to assess early changes on the right heart size and function in patients with COPD and also monitor these patients for rapid progression of the illness.

Key words: COPD-Chronic obstructive pulmonary disease, PH-Pulmonary Hypertension, RV dysfunction, CMCHChittagong Medical College Hospital.

Number of Tables: 06; Number of References: 35; Number of Correspondences: 04.

*1. Corresponding Author: Dr. Kazi Shamim Al Mamun MD

Consultant of Cardiology

17, Amirbag R/A, Chattogram.

Email: dr.mamun77@gmail.com

Mobile: +88 01713464543

2. Dr. Mohammad Ibrahim Chowdhury

MD, FCPS

Associate Professor

Department of Cardiology

Chittagong Medical College Hospital, Chattogram.

3. Dr. Muhammad Khurshed Alam

MD

Assistant Professor

Department of Cardiology

Chittagong Medical College Hospital, Chattogram.

4. Dr. Syedul Alam Khuryshi

D-card

Senior Consultant of Cardiology

Department of Cardiology

General Hospital, Khagrachari.

5. Dr. S M Ifteakharul Islam

MD

Consultant

Department of Cardiology

General Hospital, Bandarbon.

\section{Introduction:}

Chronic obstructive pulmonary disease (COPD), defined by GOLD as a preventable and treatable disease with some significant extra-pulmonary effects, is a very common clinical entity in clinical practice ${ }^{1}$. COPD is currently the 4 th leading cause of death in the world and a burning problem among the Bangladeshi population. Globally, COPD has emerged as the major cause of morbidity and mortality and is expected to become the 3rd most leading cause of death ${ }^{2}$. Cardiac manifestations are the most common extra pulmonary effects in COPD patients ${ }^{3}$. COPD affects pulmonary blood vessels, right ventricle, as well as left ventricle leading to development of pulmonary hypertension, cor-pulmonale, right ventricular dysfunction, and left ventricular dysfunction ${ }^{4}$. Right ventricle (RV) dysfunction is common in patients with COPD particularly in those with low oxygen saturation. Pulmonary hypertension $(\mathrm{PH})$ affects the right ventricle function leading to cor-pulmonale and once developed these patients have poor prognosis. So, the early recognition of RV dysfunction and pulmonary hypertension may help in treatment and prolonging the survival of the patients with cor-pulmonale. Echocardiography provides a rapid, noninvasive method to evaluate the right ventricle chamber size and function ${ }^{5}$. This study was done to identify the prevalence and degree of pulmonary hypertension by echocardiography in COPD patients. COPD affects pulmonary blood vessels, right ventricle, as well as left ventricle leading to development of pulmonary hypertension, cor-pulmonale, right ventricular dysfunction, and left ventricular dysfunction too. Echocardiography provides a rapid, noninvasive 
portable and accurate method to evaluate the right ventricle function, right ventricular filling pressure, tricuspid regurgitation, left ventricular function and valvular function ${ }^{5}$. Many studies have confirmed that echocardiographically derived estimates of pulmonary arterial pressure co-relate closely with pressures measured by right heart catheter $(r>0.7)^{6,7}$. Hence the present study was undertaken with the following aims to assess the cardiac changes secondary to COPD by echocardiography.

\section{Materials and Methods:}

The study was an observational cross sectional study. The study population consisted of patients with a diagnosis of Chronic obstructive pulmonary diseases (COPD), who were admitted to Department of Cardiology of $-(\mathrm{CMCH})$ between November 2017 and October 2018 and who subsequently, underwent Echocardiography. The inclusion and exclusion criteria were as follows:

\section{Inclusion criteria:}

1. All COPD patients attending the echocardiography room during the study period.

Exclusion criteria:

1. Patients who cannot lie for long enough to complete the study

2. $\mathrm{H} / \mathrm{O}$ of diagnosed chronic lung disease other than COPD like-

a) Interstitial lung disease,

b) Old pulmonary TB with sequalae.

3. Any systemic disease that can cause pulmonary hypertension,

Fifty (50) patients of COPD confirmed by history, clinical examination, radiology of chest, and pulmonary function test were selected from Department of Cardiology of $\mathrm{CMCH}$, Chattogram.

All selected patients were subjected to routine investigations, including complete blood count, lipid profile, blood sugar, blood urea, serum creatinine, ECG, chest X-ray, Spirometry and Urine R/E.

All patients were subjected to resting two-dimension transthoracic \& Doppler echocardiography in the Echo. Room and associated by expert cardiologists. The machine used was VIVID 6 model of GE health care system with a multifrequency probe with a range of 2-4.3 MHz. Both 2D and M-Mode studies were done. Echocardiography was reviewed to assess the pericardium, valvular anatomy and function, left and right side chamber size and cardiac function. Tricuspid regurgitant flow was identified by color flow Doppler technique and the maximum jet velocity was measured by continuous wave Doppler without the use of intravenous contrast.

Right ventricular systolic pressure was estimated based on the modified Bernoulli equation and was considered to be equal to the SPAP in the absence of right ventricular outflow obstruction: $\operatorname{sPAP}(\mathrm{mmHg})=$ right ventricular systolic pressure $=$ trans-tricuspid pressure gradient $(\mathrm{TTPG})+$ right atrial pressure (RAP), where trans-tricuspid gradient is 4v2 $(\mathrm{v}=\text { peak velocity of tricuspid regurgitation, } \mathrm{m} / \mathrm{s})^{7,8,9}$.

RV systolic function, as assessed by at least one or a combination of the following: DTI-derived tricuspid lateral annular systolic velocity wave (S'), tricuspid annular plane systolic excursion (TAPSE), and RV index of myocardial performance (RIMP). RV systolic pressure was calculated using the tricuspid regurgitation jet and an estimation of RA pressure based on inferior vena cava (IVC) size and collapsibility. Hence, pulmonary artery systolic pressure (PASP ) was calculated by using continuous wave Doppler and applying the equation below:

$\mathrm{PASP}=4 \mathrm{X}($ peak TR velocity $) 2+\mathrm{RAP}$

RAP was empirically estimated as $15 \mathrm{mmHg}$ before 1997 . Since 1997, RAP was estimated to be 5,10 , or $15 \mathrm{mmHg}$ based on the variation in the size of inferior vena cava with inspiration as follows: complete collapse, $\mathrm{RAP}=5 \mathrm{mmHg}$; partial collapse, $\mathrm{RAP}=10 \mathrm{mmHg}$; and no collapse, $\mathrm{RAP}=$ $15 \mathrm{mmHg}^{10}$.

IVC diameter $<2.1 \mathrm{~cm}$ that collapses $>50 \%$ with a sniff suggests normal RA pressure of $3 \mathrm{~mm} \mathrm{Hg}$ (range, 0-5 mm $\mathrm{Hg}$ ), whereas IVC diameter $>2.1 \mathrm{~cm}$ that collapses $<50 \%$ with a sniff suggests high RA pressure of $15 \mathrm{~mm} \mathrm{Hg}$ (range, 10-20 mm Hg). In scenarios in which IVC diameter and collapse do not fit this paradigm, an intermediate value of 8 $\mathrm{mm} \mathrm{Hg}$ (range, 5-10 mm Hg) was used ${ }^{11}$. TAPSE measures predominately the longitudinal systolic function and values $<17 \mathrm{~mm}$ is highly suggestive of RV systolic dysfunction. Right atrium pressure can be estimated with the IVC diameter and its changes with respiration.

Pulmonary hypertension ( $\mathrm{PH})$ was defined in this study as sPAP $\geq 30 \mathrm{mmHg}^{12}$. This value was chosen according to the definition of pulmonary hypertension. PH was classified into mild, moderate, and severe category as sPAP 30-50, 50-70, >70 $\mathrm{mmHg}$, respectively (using Chemla formula, mean pulmonary arterial pressure $(\mathrm{MPAP})=0.61 \mathrm{PASP}+2$ $\mathrm{mmHg}$ and putting value of $25-35,35-45$, and $>45 \mathrm{mmHg}$ of MPAP for mild, moderate, and severe pulmonary hypertension, respectively) ${ }^{13}$.

Right ventricle dimension was measured by M-Mode echo and right ventricular dilation or cor pulmonale was said to be present when it exceeded the normal range of 0.9-2.6 $\mathrm{cm}$. Right ventricle contractility was also noted and right ventricular systolic dysfunction was said to be present when it was hypokinetic.

Left ventricular function was also assessed by using the following parameters: EF (ejection fraction) $=$ measure of how much end-diastolic value is ejected from LV with each contraction $(56 \%-78 \%)$.

FS (fractional shortening) $=$ it is a percentage change in LV dimension with each LV contraction $(28 \%-44 \%)$.

LV mass = left ventricular mass (88-224 g).

$\mathrm{E} / \mathrm{A}=$ diastolic filling of left ventricles usually classified 
initially on the basis of the peak mitral flow velocity of the early rapid filling wave (E), peak velocity of the late filling wave caused by atrial contraction (A). In normal subjects $\mathrm{LV}$ elastic recoil is vigorous because of normal myocardial relaxation, therefore more filling is completed during early diastolic, so left ventricular diastolic dysfunction (LVDD) is said to be present when E/A is $<1.3$ (age group 45-49 years), $<1.2$ (age group 50-59 years), $<1.0$ (age group $60-69$ years), and $<0.8$ (age group $\geq 70$ years) ${ }^{14}$.

The calculations were done by Microsoft Excel 2007, and Statistical Package for Social Sciences, SPSS version 20; and the data were presented in the form of tables and diagrams. Appropriate statistical tests were carried out to compare the data, and a level of significance of 0.05 was used. Values were expressed as mean \pm standard deviation.

\section{Results:}

Our study included 46 (92\%) males and 4 (8\%) females, with mean age of $58.4 \pm 7.7$ years, ranging from 40 to 79 years old. Most patients had moderate to severe obstruction. Demographic characteristics and spirometric results of our cases are shown in Table-I.

Table-I: Demographic characteristics and spirometric results of the studied cases.

\begin{tabular}{lccc}
\hline Variables & Mean \pm SD & & Range \\
\hline Age (years) & $58.4 \pm 7.7$ & & $40.0-79.0$ \\
Sex & & & \\
$\quad$ Male & & $46(92)$ & \\
$\quad$ Female & & $4(8)$ & \\
Occupation & & \\
$\quad$ Mannual & & $42(84)$ & \\
$\quad$ Official & & $8(16)$ & \\
Smoker & & $03(6)$ & \\
$\quad$ Never & & $14(28)$ & \\
$\quad$ Ex-smoker & & $34(68)$ & \\
$\quad$ Current Smoker & & & $30.0-70.0$ \\
FEV1/FVC & $54.6 \pm 11.2$ & & $24.0-86.0$ \\
FEV1\% & $48.6 \pm 18.1$ & & \\
\hline
\end{tabular}

Forty seven patients (94\%) studied had significant ECG abnormality out of which $\mathrm{P}$ 'pulmonale was the most common 45 patients $(90 \%)$ while atrial arrhythmias in the form of Atrial fibrillation (AF) or Multifocal tachycardia (MAT) (6 patients, $12 \%$ ) being the least common finding (Table II).

Table-II: ECG abnormalities in COPD patients.

\begin{tabular}{lllll}
\hline Characteristics & Male $(\mathrm{n}=46)$ & Female $(\mathrm{n}=4)$ & Overall $(\mathrm{n}=50)$ & $\mathrm{p}$ value \\
\hline ECG abnormalities & $44(95.6 \%)$ & $3(74 \%)$ & $47(94 \%)$ & $>0.05$ \\
$\mathrm{P}$ ' pulmonale & $43(93.4 \%)$ & $2(50 \%)$ & $45(90 \%)$ & $<0.05$ \\
R/S ratio in V1 & $\mathrm{R} / \mathrm{S}$ ratio in V1 & $\mathrm{R} / \mathrm{S}$ ratio in V1 & $\mathrm{R} / \mathrm{S}$ ratio in V1 & $\mathrm{R} / \mathrm{S}$ ratio in V1 \\
$\quad>1$ & $30(65.2 \%)$ & $2(50 \%)$ & $32(62 \%)$ & $>0.05$ \\
$\quad<1$ & $16(34.7 \%)$ & $2(50 \%)$ & $18(36 \%)$ & $>0.05$ \\
RBBB & $18(36 \%)$ & $1(25 \%)$ & $19(38 \%)$ & $<0.05$ \\
AF/MAT & $5(10.8 \%)$ & $1(2.1 \%)$ & $6(12 \%)$ & $>0.05$ \\
\hline
\end{tabular}

Echocardiography done in the studied patients showed evidence of varying degrees of pulmonary hypertension along with enlargement of right sided chambers of the heart.
Tricuspid regurgitation peak gradient a useful marker for indirect evidence of pulmonary hypertension was studied in all the patients. Pulmonary hypertension defined as SPAP (Peak systolic pulmonary pressure) value $>30 \mathrm{mmHg}$ was observed in all of the patients in the study group. The mean TRPG value studied was $63.76 \pm 20.57 \mathrm{mmHg}$ with the range of 26-100 $\mathrm{mmHg}$ and their corresponding peak systolic pulmonary artery pressure (PASP) mean value was $75.26 \pm 21.18 \mathrm{mmHg}$. Among patients with evidence of pulmonary hypertension, 30 patients $(60 \%)$ had severe PAH, 14 patients $(28 \%)$ had moderate $\mathrm{PH}$ and 6 patients $(12 \%)$ had mild degree of pulmonary hypertension as shown in Table III.

Table-III: Pulmonary hypertension $(\mathrm{PH})$ Grade $(\mathrm{n}=50)$.

\begin{tabular}{ccc}
\hline Pulmonary hypertension & Numbers & Percentage \\
\hline Mild $(>\mathbf{3 0}-\mathbf{5 0} \mathrm{mmHg})$ & 6 & $12 \%$ \\
Moderate $(>\mathbf{5 0 - 7 0 )}$ & 14 & $28 \%$ \\
Severe $(>\mathbf{7 0} \mathbf{m m H g})$ & 30 & $60 \%$
\end{tabular}

Other parameters of right heart enlargement and function such as RA area, RV base and mid diameter, TAPSE, RIMP, S' were studied. The mean RV diameters were increased as compared to normal adult values and parameters for RV function like TAPSE and RIMP also showed that majority of patients had significant RV dysfunction in our study (Table IV).

Table-IV: Echocardiographic RV parameters.

\begin{tabular}{lcc}
\hline & Range & Mean \\
\hline RA Area (cm2) & $8.8-39$ & $20.57 \pm 6.8$ \\
RV diameter (base )/cm & $3.6-6.8$ & $5.04 \pm 0.66$ \\
RV diameter (mid)/cm & $3.4-6.8$ & $4.68 \pm 0.58$ \\
RV wall thickness /cm & $0.5-1.1$ & $0.77 \pm 0.11$ \\
TAPSE /cm & $0.9-2.3$ & $1.59 \pm 0.38$ \\
TDI s' /cm/s & $6.7-19$ & $11.5 \pm 2.95$ \\
RV MPI & $0.35-0.98$ & $0.58 \pm 0.16$ \\
TRPG /mmHg & $26-110$ & $63.76 \pm 20.57$ \\
PASP & $36-120$ & $75.26 \pm 21.18$ \\
\hline
\end{tabular}

Table-V: Frequency of cor pulmonale with severity of $\mathrm{PH}$.

\begin{tabular}{lc}
\hline Severity of PH & Frequency of cor pulmonale \\
\hline Mild (6) & $16.6 \%(1)$ \\
Moderate (14) & $71.4 \%(10)$ \\
Severe (30) & $96.6 \%(29)$
\end{tabular}

Inferior venacava diameter (IVCd) at diastole is a surrogate marker for increased right atrial pressure and is useful for estimation of peak pulmonary artery pressure. The mean IVC diameter was $1.88 \pm 0.35 \mathrm{~cm}$ as shown in -Table VI.

Table-VI: Echocardiogrpahic LV parameters and IVC size.

\begin{tabular}{lcc}
\hline & Range & Mean \\
\hline LVDD /cm & $2.8-5.7$ & $4.01 \pm 0.64$ \\
LVSD/cm & $1.5-4.5$ & $2.48 \pm 0.63$ \\
IVS/cm & $0.6-1.1$ & $0.79 \pm 0.09$ \\
\hline $\mathrm{PW} / \mathrm{cm}$ & $0.6-1.2$ & $0.82 \pm 0.01$ \\
$\mathrm{EF} \%$ & $50-65$ & $60.34 \pm 3.89$ \\
$\mathrm{IVC} \mathrm{d} / \mathrm{cm}$ & $1-2.4$ & $1.88 \pm 0.35$
\end{tabular}

*LVID - LV internal diastole diameter, LVSD- LV systole diameter, IVS - Inter-ventricular septum, PWPosterior wall thickness, EF - Ejection fraction. 


\section{Discussion:}

The cardiac manifestations of COPD are numerous. Impairment of right ventricular dysfunction and pulmonary blood vessels are well known to complicate the clinical course of COPD and co-relate inversely with survival. Significant structural changes occur in the pulmonary circulation in patients with COPD. The presence of hypoxemia and chronic ventilator insufficiency is associated with early evidence of intimal thickening and medial hypertrophy in the smaller branches of the pulmonary arteries. Coupled with these pathological changes are pulmonary vasoconstriction arising from the presence of alveolar hypoxemia, destruction of pulmonary vascular bed, changes in intrinsic pulmonary vasodilator substances (such as decrease in PGI2s (prostacyclin synthase), decrease in eNOS (endothelial nitric oxide synthase), and increase in ET1 (endothelin1) leads to remodeling, increase in blood viscosity, and alteration in respiratory mechanics. All these lead to a significant increase in pulmonary vascular resistance, the consequence of which is pulmonary hypertension. Although the true prevalence of $\mathrm{PH}$ in COPD is unknown, an elevation of pulmonary arterial pressure is reported to occur in $20 \%-90 \%$ of patients when measured by right heart catheterization with some evidence that pulmonary hemodynamic worsens with worsening airflow obstruction ${ }^{15-20}$. Two studies have shown an abnormal increase in mean pulmonary arterial pressure (Ppa) in COPD of $0.4-0.6 \mathrm{mmHg}$ per year. These studies illustrate that $\mathrm{PH}$ in COPD progresses slowly and occurs in mild as well as severe forms of disease $^{21,22}$. The level of PH has a prognostic value in COPD patients that has been demonstrated by several studies. In one of these studies, the 5-year survival rates were $50 \%$ in patients with mild $\mathrm{PH}(2030 \mathrm{mmHg}), 30 \%$ in those with moderate-to-severe $\mathrm{PH}(30-50 \mathrm{mmHg})$, and $0 \%$ in the small group of patients with very severe $\mathrm{PH}(>50 \mathrm{mmHg})$. Thus a high degree of $\mathrm{PH}$ bears a poor prognosis, and this also has been observed in COPD patients receiving long-term oxygen therapy ${ }^{23}$. In our study, all 50 patients had evidence of pulmonary hypertension ( $\mathrm{sPAP}>30 \mathrm{mmHg}$ ) with majority of them $(60 \%)$ having higher grades of pulmonary hypertension maybe because of the chronicity of the disease and the study was mainly done in admitted patients with COPD. There was significant evidence of right ventricular enlargement as well as decline in RV systolic function through various parameters studied by echocardiography. All COPD patients studied had shown an increase in RV enlargement in form of increased RV diameters ( $\mathrm{RV}$ base $=5.04 \pm 0.66$ and $\mathrm{RV}$ mid $=4.68 \pm 0.58 \mathrm{~cm})$. RV systolic function as assessed by TAPSE and RIMP also showed values below normal adult population values which indicate majority of COPD patients studied had evidence of RV dysfunction as well. (TAPSE, mean $=1.59 \pm 0.38$, RIMP $=0.58 \pm 0.16$ ). Saxena $\mathrm{N}$ et al. ${ }^{24}$ showed tricuspid annular systolic velocity (TAPSE) is a useful measurement in determining right ventricular systolic function regardless of pulmonary artery pressures in a study of 52 patients.
Evidence of right ventricular hypertrophy was also seen in most patients with the average RV wall thickness of $0.77 \pm 0.11 \mathrm{~mm}$ as compared to normal adult value of 3-5 $\mathrm{mm}$. In the current study, no motion wall abnormalities were found in the echo findings of the patients. This disagreed with Freixa et al. ${ }^{25}$ who found that $30 \%$ of patients with LVSD presented left ventricle wall motion abnormalities. This difference might be owing to a large number of included-patients. In current study, no statistical significant correlation was found between left ventricular systolic function and dimensions and the severity of COPD. This is similar to Freixa et al. ${ }^{25}$. Frequent reports about the prevalence of LVDD in patients with COPD have been shown in many studies. The prevalence of LVDD in this study was $20 \%$. This was in contrary to Huang and colleagues, who showed a higher frequency of LVDD in patients with COPD (65.6\%) and Caram and colleagues who reported high frequency up to $88 \%$. Another study by Lopez Sanchez et al. ${ }^{28}$ focused on severe COPD outpatients and showed a highest prevalence of LVDD $(90 \%)^{26,27}$. In this study, there was no correlation between LVDD and the severity of COPD. This is similar to the study conducted by Huang et al. ${ }^{26}$. The current study showed that RV dilatation was found in early stages of COPD. This agreed with Hilde et al. ${ }^{29}$. Moreover, there was a positive correlation between severity of COPD and RV size. This is similar to the study conducted by Jatav et al. ${ }^{30}$. In the present study, tricuspid regurgitation was present in $\sim 75 \%$ of the patients with variable grades from mild to severe. There was a positive correlation between grades of obstruction and tricuspid regurgetation. Similar findings were observed in study of Maula et al. ${ }^{31}$. True prevalence of PH in COPD is unknown. A reported elevation of pulmonary arterial pressure is between 20 and $90 \%$ measured by right heart catheterization, with some evidence that $\mathrm{PH}$ increases with increase airflow obstruction $^{32,33,34}$. The current study showed that the presence of $\mathrm{PH}$, that is, moderate pulmonary artery systolic pressure more than $50 \mathrm{mmHg}$, was $28 \%$. PH appeared more in severe and very severe grades of the disease than in mild/moderate disease. These results agreed with Jatav et al. ${ }^{30}$ and El Wahsh et al. ${ }^{35}$ who showed that increased pulmonary artery systolic pressure was found in 44 and $55.56 \%$ of patients, respectively, and also showed a positive correlation with severity of COPD. Most of the patients (12\%) in the current study with $\mathrm{PH}$ had mild degree of $\mathrm{PH}$, and this was in agreement with Freixa et al. ${ }^{25}$ who found that the magnitude of $\mathrm{PH}$ was mild in most cases and only $3 \%$ of patients had severe PH. In the current study, TAPSE was used as easily obtainable measure of RV systolic function, and it was normal in all patients, who is in contrary to Hilde et al. ${ }^{20}$ who included some patients with COPD with very severe degree of obstruction with respiratory failure and TAPSE was lower in them than controls. In this study, there were some limitation such as using two-dimensional Doppler echocardiogram with color flow without using 
tissue Doppler echocardiography, which made the assessment of prevalence of LVDD less accurate. Right heart catheterization was not available for definitive diagnosis of $\mathrm{PH}$ and detection of its prevalence.

\section{Conclusion:}

This study reveals that chronic obstructive pulmonary disease with pulmonary hypertension is highly prevalent in our country. Echocardiographic right heart profile assessment should be an additional tool to detect and prognosticate patients with various degrees of pulmonary hypertension.

\section{Conflict of Interest: None.}

\section{Acknowledgement:}

We are thankful to the entire team of Cardiology Department specially Echo room Staff for their contribution to conduct the study smoothly.

\section{References:}

1. N. K. Gupta, Ritesh Kumar Agrawal, A. B. Srivastav, M. L. Ved. Echocardiographic evaluation of heart in chronic obstructive pulmonary disease patient and its co-relation with the severity of disease. Lung India. Apr - Jun 2011; 28(2):105-109.

https://doi.org/10.4103/0970-2113.80321

PMid:21712919 PMCid:PMC3109831

2. Murray CJ, Lopez AD. Evidence based health policy-lessons from the Global Burden of disease Study. Science. 1996; 274:740- 743 .

https://doi.org/10.1126/science.274.5288.740

\section{PMid:8966556}

3. Kasibowska-Kuzniar K, Jankowska R, Kuzniar T. Chronic obstructive pulmonary disease exacerbation - effects on quality of life. Pol Arch Med Wewn. 2005; 114: 1010-1015. 4. Gupta, N. K. Echocardiographic evaluation of heart in chronic obstructive pulmonary disease patient and its co-relation with the severity of disease. Lung India: official organ of Indian Chest Society 2011, 28(2): 105-109.

https://doi.org/10.4103/0970-2113.80321

PMid:21712919 PMCid:PMC3109831

5. Daniels LB, Krummen DE, Blanchard DG. Echocardiography in pulmonary vascular disease.CardiolClin. 2004; 22:383-99.

https://doi.org/10.1016/j.ccl.2004.04.007

PMid:15302359

6. Tramarin R, Torbicki A, Marchandise B, Laaban JP, Morpurgo M. Doppler echocardiographic evaluation of pulmonary artery pressure in chronic obstructive pulmonary disease. A European multicentre study. Eur Heart J. 1991; 12:103-11.

https://doi.org/10.1093/oxfordjournals.eurheartj.a059855

PMid:2044542

7. Yock PG, Popp RL. Noninvasive estimation of right ventricular systolic pressure by Doppler ultrasound in patients with tricuspid regurgitation. Circulation. 1984; 70:657-62.

https://doi.org/10.1161/01.CIR.70.4.657

PMid:6478568

8. Currie PJ, Seward JB, Chan KL, Fyfe DA, Hagler DJ, Mair DD, et al. Continuous wave Doppler estimation of right ventricular pressure: A simultaneous Doppler-catheterization study in 127 patients. J Am Coll Cardiol. 1985; 6:750-6.

https://doi.org/10.1016/S0735-1097(85)80477-0

9. Chan KL, Currie PJ, Seward JB, Hagler DJ, Mair DD, Tajik AJ. Comparison of three Doppler ultrasound methods in the prediction of pulmonary artery pressure. J Am Coll Cardiol. 1987; 9:549-54.

https://doi.org/10.1016/S0735-1097(87)80047-5

10. Bredikis AJ, Liebson PR. The echocardiogram in COPD: Estimating right heart pressures. J Respir Dis. 1998; 19:191-8.

11. Brennan JM, Blair JE, Goonewardena S, Ronan A, Shah D, Vasaiwala S, et al. Reappraisal of the use of inferior vena cava for estimating right atrial pressure. J Am SocEchocardiogr. 2007; 20:857-61.

https://doi.org/10.1016/j.echo.2007.01.005

PMid: 17617312

12. Rappaport E. Cor pulmonale. In: Murray JJ, Nadel JA, Mason RM, Boushey H (eds). Textbook of respiratory medicine. 4th Edition. Philadelphia: W.B. Saunders; 2000:1631-48.

13. Chemla D, Castelain V, Humbert M, Simonneau JLHG, Lecarpentier Y, Hervé P. New Formula for Predicting Mean Pulmonary Artery Pressure Using Systolic Pulmonary Artery Pressure: Chest. 2004;126;1313-17.

https://doi.org/10.1378/chest.126.4.1313

PMid: 15486398

14. Libby P, Bonow RO, Zipes DP, Mann DL. Braunwald's Heart Disease. 8th Edition. Philadelphia: Saunders ; 2008: 251. 15. Weitzenblum E, Hirth C, Ducolone A, Mirhom R, Rasaholinjanahary J, Ehrhart M. Prognostic value of pulmonary artery pressure in chronic COPD. Thorax. 1981;36:752-8.

https://doi.org/10.1136/thx.36.10.752

PMid:7330793 PMCid:PMC471749

16. Weitzenblum E, Sautegeau A, Ehrhart M, Mammosser M, Hirth C, Roegel E. Long term course of pulmonary artery pressure in chronic COPD. Am Rev Respir Dis. 1984;130:993-8.

17. Burrows B, Kettel LJ, Niden AH, Rabinowitz M, Diener CF. Patterns of cardiovascular dysfunction in COPD. N Engl J Med. 1972;286:912-8.

https://doi.org/10.1056/NEJM197204272861703

PMid:5013974 
18. Fishman AP. State of the art: Chronic cor pulmonale. Am Rev Respir Dis. 1976;114:775-94.

19. Pietra G. Pathology of the pulmonary vasculature and heart. In: Cherniack N, editor. COPD. Philadelphia: WB Saunders; 1996: 21-6.

20. Thabut G, Dauriat G, Stern JB, Logeart D, Lévy A, Marrash-Chahla R, et al. Pulmonary haemodynamics in advanced COPD candidates for lung volume reduction surgery or lung transplantation. Chest. 2005;127:1531-6.

https://doi.org/10.1378/chest.127.5.1531

PMid: 15888824

21. Weitzenblum E, Sautegeau A, Ehrhart M, Mammosser $\mathrm{M}$, Pelletier A. Long-term oxygen therapy can reverse the progression of pulmonary hypertension in patients with chronic obstructive pulmonary disease. Am Rev Respir Dis. 1985;131:493-8.

https://doi.org/10.1164/arrd.1985.131.4.493

PMid:3922267

22. Kessler R, Faller M, Weitzenblum E, Chaouat A, Aykut A, Ducolone'A, et al. "Natural history" of pulmonary hypertension in a series of 131 patients with chronic obstructive pulmonary disease. Am J Respir Crit Care Med. 2001;164:219-24.

https://doi.org/10.1164/ajrccm.164.2.2006129

PMid:11463591

23. Oswald-Mammosser M, Weitzenblum E, Quoix E, Moser G, Chaouat A, Charpentier C, et al. Prognostic factors in COPD patients receiving long-term oxygen therapy. Chest. 1995;107:1193-8.

https://doi.org/10.1378/chest.107.5.1193

PMid:7750305

24. Saxena N. Tricuspid annular systolic velocity: a useful measurement in determining right ventricular systolic function regardless of pulmonary artery pressures. Echocardiography. 2006 Oct; 23(9): 750-5.

https://doi.org/10.1111/j.1540-8175.2006.00305.x

PMid:16999693

25. Freixa X, Portillo K, Paré C, Garcia-Aymerich J, Gomez FP, Benet M, et al. Echocardiographic abnormalities in patients with COPD at their first hospital admission. Eur Respir J. 2013; 41:784-791.

https://doi.org/10.1183/09031936.00222511

PMid:23018914

26. Huang YS, Feng YC, Zhang J, Bai L, Huang W, Li W, et al. Impact of chronic obstructive pulmonary diseases on left ventricular diastolic function in hospitalized elderly patients. Clin Interv Aging. 2015; 10:81-87.

https://doi.org/10.2147/CIA.S71878

PMid:25565790 PMCid:PMC4279668
27. Caram LM, Ferrari R, Naves CR, Tanni SE, Coelho LS, Zanati SG, et al. Association between left ventricular diastolic dysfunction and severity of chronic obstructive pulmonary disease. Clinics (Sao Paulo). 2013; 68:772-776. https://doi.org/10.6061/clinics/2013(06)08

28. Lopez-Sanchez M, Munoz-Esquerre M, Huertas D, Gonzalez-Costello J, Ribas J, Manresa F, et al. High prevalence of left ventricle diastolic dysfunction in severe COPD associated with a low exercise capacity: a cross-sectional study. PLOS ONE. 2013; 8:e68034.

https://doi.org/10.1371/journal.pone.0068034

PMid:23826360 PMCid:PMC3694927

29. Hilde JM, Skjorten I, Grotta OJ, Hansteen V, Melsom $\mathrm{MN}$, Hisdal J, et al. Right ventricular dys- function and remodeling in chronic obstructive pulmonary dis- ease without pulmonary hypertension. J Am Coll Cardiol. 2013; 62:1103-1111.

https://doi.org/10.1016/j.jacc.2013.04.091

PMid:23831444

30. Jatav VS, Meena SR, Jelia S, Jain P, Ajmera D, Agarwal $\mathrm{V}$, et al. Echocardiographic findings in chronic obstructive pulmonary disease and correlation of right ventricular dysfunction with disease severity. IJAM. 2017; 4:476-480.

https://doi.org/10.18203/2349-3933.ijam20171045

31. Maula F, Nadeem M, Adil M, Ullah J, Rauf A. echocardiographic findings in chronic pulmonary disease(COPD) patients. PJCM. 2012;2309-9844.

32. Shujaat A, Bajwa AA, James D. Cury. Pulmonary hypertension secondary to COPD. Pulm Med. 2012; 2012:203952.

https://doi.org/10.1155/2012/203952

PMid:22973510 PMCid:PMC3437672

33. Weitzenblum E, Hirth C, Ducolone A, Mirhom R, Rasaholinjanahary J, Ehrhart M. Prognostic value of pulmonary artery pressure in chronic COPD. Thorax. 1981; 36:752-758.

https://doi.org/10.1136/thx.36.10.752

PMid:7330793 PMCid:PMC471749

34. Thabut G, Dauriat G, Stern JB, Logeart D, Levy A, Marrash-Chahla R, et al. Pulmonary hemodynamics in advanced COPD candidates for lung volume reduction surgery or lung transplantation. Chest. 2005; 127:1531-1536.

https://doi.org/10.1378/chest.127.5.1531

PMid: 15888824

35. El Wahsh RA, Ahmed MK, Yaseen RI. Evaluation of left ventricular function in patients with chronic obstructive pulmonary disease with or without pulmonary hypertension. Egypt J Chest Dis Tuber. 2013; 62:575-582.

https://doi.org/10.1016/j.ejcdt.2013.08.004 